\title{
The Age-Related Changes in Cartilage and Osteoarthritis
}

\author{
YongPing Li, ${ }^{1}$ XiaoChun Wei, ${ }^{1}$ JingMing Zhou, ${ }^{2}$ and Lei Wei ${ }^{1,2}$ \\ ${ }^{1}$ Department of Orthopaedics, The Second Hospital of Shanxi Medical University, 382 Wuyi Road, Taiyuan, Shanxi 030001, China \\ ${ }^{2}$ Department of Orthopaedics, The Warren Alpert Medical School of Brown University/Rhode Island Hospital, \\ 1 Hoppin Street, Providence, RI 02903, USA
}

Correspondence should be addressed to XiaoChun Wei; weixc666@163.com

Received 3 April 2013; Revised 7 June 2013; Accepted 9 June 2013

Academic Editor: Vijay K. Goel

Copyright (c) 2013 YongPing Li et al. This is an open access article distributed under the Creative Commons Attribution License, which permits unrestricted use, distribution, and reproduction in any medium, provided the original work is properly cited.

Osteoarthritis $(\mathrm{OA})$ is closely associated with aging, but its underlying mechanism is unclear. Recent publications were reviewed to elucidate the connection between aging and OA. With increasing OA incidence, more senior people are facing heavy financial and social burdens. Age-related OA pathogenesis is not well understood. Recently, it has been realized that age-related changes in other tissues besides articular cartilage may also contribute to OA development. Many factors including senescence-related secretory phenotypes, chondrocytes' low reactivity to growth factors, mitochondrial dysfunction and oxidative stress, and abnormal accumulation of advanced glycation end products (AGEs) may all play key roles in the pathogenesis of age-related OA. Lately, epigenetic regulation of gene expression was recognized for its impact on age-related OA pathogenesis. Up to now, few studies have been reported about the role of miRNA and long-noncoding RNA (lncRNA) in age-related OA. Research focusing on this area may provide valuable insights into OA pathogenesis. OA-induced financial and social burdens have become an increasingly severe threat to older population. Age-related changes in noncartilage tissue should be incorporated in the understanding of OA development. Growing attention on oxidative stress and epigenetics will provide more important clues for the better understanding of the age-related OA.

\section{Introduction}

Half of the world's population, aged 65 and older, suffers from OA [1]. Many studies showed that increased age is the most prominent risk factor for the initiation and progression of primary OA in typically affected joints including interphalangeal, hips, knees, and intervertebral. The rare cases of OA diagnosed in young individuals, under the age of 25-30 years old, are mostly due to mutations in matrix genes that cause significant structural abnormalities and/or joint deformities [2-4].

To this day, the mechanism of OA has not been fully clarified. Current hypotheses include the classic "wear and tear" theory $[2,4]$, senescence-related secretory phenotype [5], chondrocytes' low reactivity to growth factors [6], mitochondrial dysfunction and oxidative stress [7], and abnormal accumulation of advanced glycation end products (AGEs) [8]. The cumulative effect of mechanical load over the years may cause "wear and tear" clinically and cartilage breakdown pathologically [2]. Hence, OA is regarded as a naturally occurring irreversible phenomenon, rather than a specific, potentially treatable disease. However, OA is not inevitable for all senior adults (age 60+). It has become increasingly clear that OA is not a purely mechanical problem [9]. Age-related changes in cartilage extracellular matrix proteins such as collagen or proteoglycans can induce nonenzymatic collagen cross-linking and shorten aggrecan molecules [9]. Excessive collagen cross-linking affects the biomechanical properties of cartilage, causes increased stiffness, and makes cartilage more brittle [10] and susceptible to fatigue failure [11]. Shortening and degradation of aggrecan leads to significant loss of sugar side chains and water-binding ability [12]. In addition, increased levels of AGEs are associated with a decline in anabolic activity [13]. These findings suggest that age-related changes in matrix may play a role in the development of OA.

Lately, it has been gradually realized that age-related changes occurring in tissues besides articular cartilage may contribute to the development of OA [9]. Because articular cartilage lacks nerve supply, knee pain could be attributed to 
OA-related changes of the joint tissues, such as the synovium, bone (including osteophytes), joint capsule, ligaments, and menisci [14]. These tissues could play important roles in the early stages of OA [14]. Thus, OA is considered a "whole joint disease" [9]. Although it raises the complexity of OA, this concept improved our understanding of the disease as well as indicated potential new treatment strategies [9].

This review focuses on recent studies that shed light on the connection between aging changes in cells and tissues and the propensity for OA occurrence in older adults.

\section{Epidemiology}

$\mathrm{OA}$ is the most common joint disorder in the world and one of the most common sources of pain and disability in the elderly $[15,16]$. The incidence of OA is predicted to increase as the senior population grows, placing a significant financial burden on healthcare providers and governments [17]. OA affects at least 27 million Americans and is the leading cause of disability in the United States [17]. Compared to only $7.6 \%$ of those $18-44$ years of age and $29.8 \%$ of those $45-64$ years of age, $50 \%$ of individuals older than 65 years are diagnosed with this disease [17]. OA affects one in six adults, and by 2030 it is estimated that $20 \%$ of people in Europe and the United States will suffer from OA [18]. The senior population is growing rapidly in many Asian countries [19]. It is estimated that the $65+$ population in Asia will more than double in the next two decades, increasing from $6.8 \%$ in 2008 to $16.2 \%$ in 2040 . In most of the developed world demographic change is a gradual progress following the steady socioeconomic growth over several decades. In contrast, this change is compressed into 2-3 decades in many Asian countries. For example, during the period between 2008 and 2040, it is estimated that the 65+ population will increase by $316 \%$ in Singapore, $274 \%$ in India, $269 \%$ in Malaysia, 261\% in Bangladesh, and 256\% in the Philippines. In 2008, Japan had the world's oldest population (people $65+$ represented $21.6 \%$ of whole population), and both China and India were ranked top two for the size of 65+ population (106 and 60 million, resp.) [16]. The high prevalence and heavy impact on working capacity make OA a major social issue [20]. Therefore, healthcare and socioeconomics need to put a high priority to the prevention and treatment of OA [18].

OA in humans usually becomes symptomatic after age 50 , which is also when the radiographic changes of OA become more common [4]. Although radiographic signs of OA such as osteophytes and joint space narrowing do not always correlate well with symptoms, epidemiologic studies of large cohorts commonly depend on radiographs to define OA [4]. Goekoop et al. examined a cohort of 90-year olds living in the city of Leiden in Netherlands and found that only $16 \%$ of people in that age were free of radiographic OA [21].

In the Johnson Country OA cohort [22], the prevalence of radiographic knee OA rose from $26.2 \%$ in the 55-64 age group to nearly $50 \%$ in the $75+$ age group, and the prevalence of symptomatic knee OA likewise increased from $16.3 \%$ to $32.8 \%$ between these age groups. Symptomatic hip OA in this cohort was reported as $5.9 \%$ in the $45-54$ age group compared with $17 \%$ in the $75+$ age group. In the Johnston County
OA Project, African American men had a higher prevalence of radiographic hip OA than Caucasian men (32.2\% versus $23.8 \%$ ), whereas no difference was found between African American and Caucasian women (40.3\% versus 39.4\%) [23]. Individual radiographic features in hip and knee were also noted to differ between two ethnic groups [24, 25]. In the Beijing OA Study, hand and hip OA were less prevalent among Chinese than Caucasians (age-standardized prevalence $44.5 \%-47 \%$ versus $75.2 \%-85 \%$ and $0.8 \%$ versus $3.8-$ $4.5 \%$, resp.), but knee OA was more prevalent among Chinese women than Caucasian women (46.6\% versus 34.8\%) [16, 18, 26].

The heritability of OA is estimated to be $40 \%$ to $65 \%$ and is higher for hand and hip OA than for knee OA [27-29]. So far, 3 loci have been associated to $\mathrm{OA}$ at genome-wide significant levels [30-32], that is, GDF5, which encodes the growth differentiation factor 5 (a bone morphogenetic protein expressed in skeletal and articular structures), chromosome 7q22, and MCF2L (MCF.2 cell line derived transforming sequence-like). Pain severity in OA may also have genetic contributions. A functional polymorphism (Val158Met) in the COMT gene, which was previously correlated with pain sensitivity in other clinical conditions, was associated with hip OA-related pain in a cohort study [33]. TRPV1 and the PACE4 gene Pcsk6 were associated with pain in knee OA in two separate meta-analyses $[34,35]$.

\section{Chondrocyte Changes}

The primary function of chondrocytes is to maintain cartilage homeostasis, in part through the production of extracellular matrix components. With age, chondrocytes exhibit features similar to senescent phenotypes, including telomere shortening and increased senescence-associated $\beta$-galactosidase activity $[5,36]$. These age-related changes impair the ability of chondrocytes to maintain the surrounding extracellular matrix. Accordingly, in aged chondrocytes, synthetic activity is decreased and proteoglycans are smaller and more irregular $[37,38]$.

A reduction in the number of chondrocytes was observed in normal articular cartilage during aging, comparing with a greater loss of chondrocytes in OA cartilage, but the extent of cell death is debatable [39-41]. A study showed 30\% drop in cell density in human hip joint cartilage between the ages of 30 and 70 [42]. However, a study on human knees found less than $5 \%$ cell loss during aging [43]. Loss of the chondrocytes can be attributed to increased chondrocyte death and/or apoptosis. Although many studies reported apoptotic chondrocytes in OA cartilage [41], few have examined apoptosis in cartilage with normal aging, except for one study on rat cartilage [44]. There is evidence showing [45] that HMGB2, a high-mobility group box (HMGB) protein that may be important for chondrocyte survival, regulates gene transcription through chromatin organization. HMGB2 is mainly expressed in chondrocytes in the superficial zone of articular cartilage, and HMGB2 levels drop during aging [45]. Moreover, the decline in HMGB2 levels was associated with increased chondrocyte death, and HMGB2-deleted mice developed premature OA [45]. Levels of reactive oxygen 
species (ROS) are increased in cartilage during aging, and chondrocytes from older adults are more susceptible to ROSmediated cell death [46].

The synthetic activity of chondrocytes is regulated by anabolic growth factors [47]. During aging, chondrocytes exhibit reduced responsiveness to growth factors, such as insulin-like growth factor-1 (IGF-1) [6, 48, 49], osteogenic protein-1 (OP-1) or bone morphogenic protein-7 [50], and transforming growth factor- $\beta$ (TGF- $\beta$ ) [51, 52]. For example, TGF- $\beta$ stimulates proteoglycan synthesis in young animals, but this ability is impaired in old mice [51, 53]. It is hypothesized that age-related alterations in the TGF- $\beta$ signaling pathway trigger chondrocytes to leave their normally quiescent state into an autolytic phenotype, leading to degradation of cartilage extracellular matrix [54]. Reduced anabolic response to IGF-I was also noted in chondrocytes isolated from OA cartilage $[48,55]$. These findings suggest that agerelated decline in anabolic activity could tip the balance towards increased catabolism and play a key role in increasing cartilage susceptibility to OA.

Age-related changes inside chondrocytes including cellular senescence and reduced responsiveness to growth factors and extracellular factors affecting chondrocyte aging such as AGE accumulation and oxidative stress may work together to disrupt cartilage homeostasis. These changes will make the cartilage matrix more vulnerable to damage and lead to the onset of OA. The onset of OA is characterized by increased cell proliferation, which leads to formation of chondrocyte clusters and increased synthesis of irregular matrix components such as collagens and proteoglycans [56-58]. With OA progression, excessive catabolic activity causes imbalance of cartilage homeostasis and cartilage matrix breakdown. These catabolic events are largely mediated by proinflammatory cytokines and mediators, for example, matrix metalloproteinases (MMPs), and a disintegrin and metalloproteinase with thrombospondin motifs (ADAMTS) [59]. Notably, many characteristics of an aged chondrocyte parallel changes observed in early OA, which might explain why age is highly correlated to OA [60].

AGEs are produced through a nonenzymatic reaction between reducing sugars and free amino groups of proteins, lipids, or nucleic acids [61]. Excessive levels of AGEs in the body are pathogenic, resulting in elevated oxidative stress and inflammation [62]. In chondrocytes, AGEs can increase the production of inflammatory cytokine tumor necrosis factor$\alpha$ (TNF- $\alpha$ ), inflammatory mediators prostaglandin E2, and nitric oxide. It can also suppress the production of type II collagen and stimulate the expression of degradative enzyme MMPs and ADAMTS [8, 63, 64]. AGEs accumulation also has adverse effects on the cartilage extracellular matrix. AGEs increase collagen cross-linking, which enhances tissue stiffness, making cartilage more brittle and susceptible to mechanical failure $[10,11,65]$. Although not reported in chondrocytes, AGEs also induce ROS generation in murine hepatic stellate cells and bone marrow mesenchymal stem cells $[66,67]$.

ROS play important roles in many physiological processes and can potentially cause oxidative damages to proteins, lipids, and DNA [68]. Human articular chondrocytes actively produce ROS, and increased levels of ROS were observed in articular cartilage of old rats compared to young rats [69-72]. Furthermore, cartilage of old rats exhibited a significant drop in antioxidant catalase activity [72]. This redox imbalance may be caused by an age-related decline in the activity and number of mitochondria, which play critical roles in protecting cells from ROS damage [7]. The consequence of increased oxidative stress is DNA damage and telomere shortening, leading to reduced matrix production, chondrocyte senescence, and apoptosis [73-75]. Increased ROS also upregulate proinflammatory cytokines and MMPs, factors that mediate cartilage degradation [76].

Mitochondria is a major source of ROS in the cell, and mitochondrial dysfunction is thought to play a key role in age-related diseases including OA. Evidence has been shown that mitochondrial DNA damage in OA is promoted by inflammatory cytokines such as IL-1 $\beta$ and TNF- $\alpha$ and contributes to chondrocyte death [76]. Mechanical injury to cartilage, such as articular cartilage crushing, shearing force injury, would result in elevated ROS generation in mitochondria and promotes chondrocyte death [77]. Subchondral bone softening, which occurs during age-related osteoporosis [78], is predicted to alter the biomechanics of the tibiofemoral joint by increasing the maximum tensile strains in cartilage and the magnitudes of joint contact pressure [79]. In addition, due to the aged less activity, the declined quadriceps strength may be another factor responsible for altered joint loading patterns as a consequence of joint laxity [80]. Nonphysiological load or less mechanical load exerted on chondrocytes would induce catabolic signaling and cartilage tissue breakdown [59].

ROS could play a key role in age-related chondrocyte changes in several signaling pathways [81]. Excessive levels of ROS were found to inhibit activation of the IRS-1-PI-3 kinaseAkt signaling pathway, which normally promotes matrix synthesis [81] (Figure 1). Meanwhile, ROS activates the ERK MAP kinase which suppresses the expression of chondrocyte aggrecan, type II collagen, and Sox-9 [77] (Figure 1). Sustained activation of ERK can induce cell senescence. A study [82] using rat chondrosarcoma cells demonstrated that sustained ERK activation mediated by FGFR3 promoted the expression of the senescent phenotype markers. Extracellular ROS could also contribute to inhibition of the Akt pathway through oxidized low-density lipoprotein (LDL). The binding of oxidized LDL to cell surface receptor LOX-1 was found to induce chondrocyte senescence, possibly by inhibiting Akt phosphorylation upon IGF-1 stimulation [83] (Figure 1). Oxidative stress induced by oxidized LDL is also associated to promotion of hypertrophic chondrocyte phenotype in $\mathrm{OA}$ cartilage [84].

A study [85] on the expression of the superoxide dismutase (SOD) family of antioxidants demonstrated decreased expression of all three SOD isoforms (copper/zinc $(\mathrm{Cu} / \mathrm{Zn})$ SOD, manganese (Mn)-SOD, and extracellular (EC)-SOD), at the transcriptional level. Decreased expression of mitochondrial SOD (SOD2) was associated with increased methylation inSOD2 promoter region suggesting that epigenetic regulation may be involved in inhibition of the expression of this antioxidant gene [85]. A more recent study reported that 


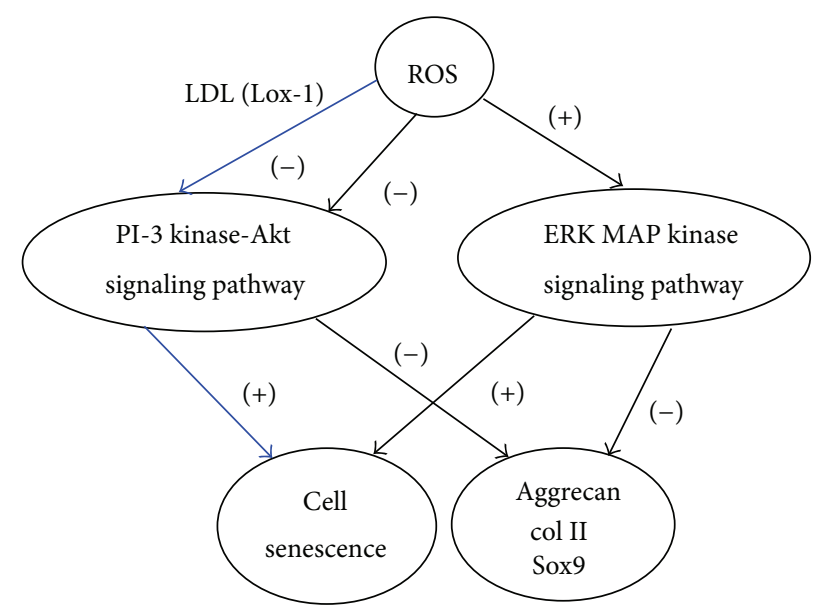

FIGURE 1: Schematic diagram showing the key role of ROS in age-related chondrocyte changes. Excessive levels of ROS inhibited matrix synthesis (aggrecan, type II collagen) by suppressing the IRS-1-PI-3 kinase-Akt signaling pathway or by activating the ERK MAPK signaling pathway. Sustained activation of ERK can induce cell senescence. In addition, extracellular ROS could also contribute to the inhibition of the Akt pathway through oxidized low-density lipoprotein (LDL). The binding of oxidized LDL to cell surface receptor LOX-1 was found to induce chondrocyte senescence (blue arrow).

people in Spain with mitochondrial DNA haplotype J, which is associated with a lower risk of OA, have lower serum levels of MMP-13 when compared to those with haplotype $\mathrm{H}$, who have higher serum levels of MMP-3 [86]. It is possible that the different haplotypes are characterized by different ROS generation and perhaps different amount of mitochondrial DNA damage, although this is not fully established. Interestingly, a study examining a murine model of premature aging that exhibits increased nuclear DNA damage due to deficiency of a repair enzyme found a significant increase in age-related bone loss but not in cartilage damage [87].

\section{The Changes in Cartilage Matrix}

Age-related changes not only occur in chondrocytes but also in cartilage matrix, thereby contributing to OA development. MRI studies showed that knee cartilage thins during aging, particularly on the femoral side of the joint [88] and in patellae [89], suggesting a gradual loss of cartilage matrix with age. This could be due to loss of chondrocytes and reduced growth factor activity, but also to something as simple as reduced water content. Type II collagen, the most abundant matrix protein in cartilage, has a half-life over 100 years [90]. Excessive collagen cross-linking increases stiffness and brittleness [10], thereby increasing susceptibility to fatigue failure [11]. Increased levels of AGEs in cartilage are correlated with declined anabolic activity [13]. Being the second most abundant cartilage matrix protein, aggrecan is a large "aggregating" proteoglycan consisting of a core protein and numerous highly sulfated glycosaminoglycan chains that are covalently attached [91]. Because of the hydrophilic nature of aggrecan's negatively charged sulfates, articular cartilage has about $70-80 \%$ water content and is very resilient. Age-related changes in size, structure, and sulfation of aggrecan [12, 37, 91, 92] affect cartilage resiliency and hydration [93]. When aggrecan is degraded, a fragment containing the binding region for hyaluronic acid is left behind and appears to accumulate in cartilage with age due to a low turnover rate with an estimated aggrecan half-life of 25 years in cartilage [94].

The balance of anabolism to catabolism is regulated by the fine-tuning of the specific genes in certain signaling pathways. Studies using transgenic and knockout mice continue to provide information on specific genes that may play a role in OA progress [95]. FGFR3 knockout mice [96] were found to develop more severe OA with age than FGFR1 knockout mice [97]. Together, these results suggest an anabolic/joint protective function of FRGFR3 and a catabolic/joint destructive function for FGFR1.

Transforming growth factor- $\beta$ (TGF- $\beta$ ) is secreted in an inactive form and requires activation before binding to its receptor [98]. Activated TGF- $\beta$ binds to the TGF- $\beta$ type II receptor and forms a complex that recruits the TGF- $\beta$ type I receptor, ALK5. However, TGF- $\beta$ is also able to signal via the alternative TGF- $\beta$ type I receptor ALK1 in chondrocytes [99] (Figure 2). In endothelial cells as well as chondrocytes, activation of ALK5 is followed by Smad2 or Smad3 phosphorylation, while ALK1 activation results in phosphorylation of Smad1, Smad5, or Smad8 [54, 99-101] (Figure 2). The activated Smads form a complex with the co-Smad Smad4 and translocate to the nucleus to modify gene expression. Interestingly, signaling via either ALK5 or ALK1 can turn the response of cells to TGF- $\beta$ stimulation in opposite directions $[54,102]$ (Figure 2). For example, in endothelial cells ALK5 inhibits migration, whereas ALK1 stimulates migration and proliferation [103]. The Smad pathway appears to be the most important for TGF- $\beta$ signaling but is not the only option. Mitogen-activated protein kinase, Rho-like GTPase, and phosphatidylinositol-3-kinase pathways are involved in TGF$\beta$ signaling [104]. Activation of TGF- $\beta$ activated kinase 1 (TAK1) happens independently of ALK5 kinase activity and induces P38 and JNK signaling [105]. Studies on activin receptor-like kinases (ALKs) activated by TGF- $\beta$ showed that ALK5 activation is proanabolic, and ALK1 activation is procatabolic [106] (Figure 2). During aging and in OA, the ratio of ALK1 to ALK5 is increased to promote OA development, and the ratio of FGFR1 to FGFR3 may change in a similar way [107].

In our previous study, we demonstrated the loss of TGF$\beta$ type I receptor ALK5 and phosphorylation of Smad2/3 in murine articular cartilage during aging [108], but the expression of total Smad 2 was not altered by TGF- $\beta$. Moreover, in two experimental models of OA-the DMM (meniscus destabilization) model and the STR/ORT mice (spontaneous OA model) - development of the disease was correlated with decreased ALK5 expression. Expression of the alternative TGF- $\beta$ receptor ALK1 did not decrease to a similar extent as ALK5 [109]. STR/ORT mice develop OA starting at the medial tibia from an age of 2 to 3 months. The ALK1/ALK5 ratio was 5 on the medial tibia at the age of 3 months and was 18 in 1-year-old animals. The lateral tibia showed increased 


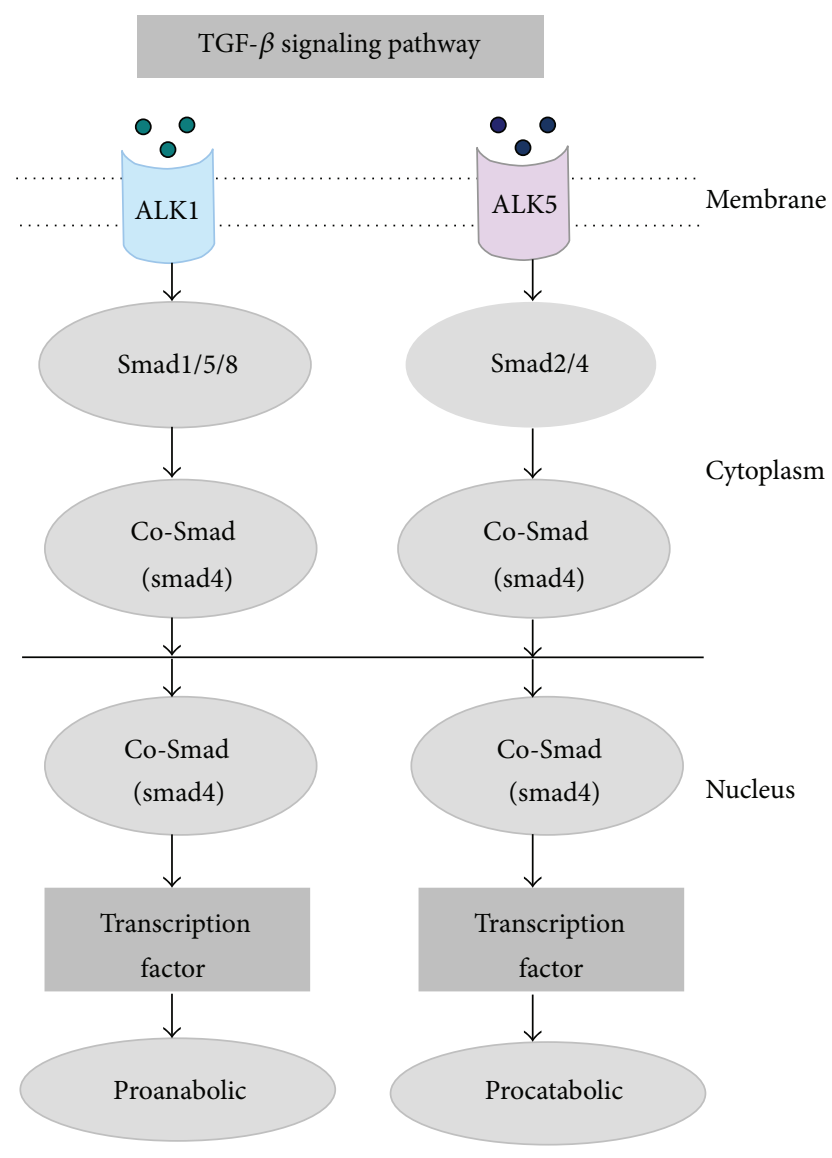

FIgURE 2: Schematic diagram showing that cartilage matrix homeostasis is adjusted dynamically by TGF- $\beta$ signaling pathway. Activated TGF- $\beta$ binds to the TGF- $\beta$ type I receptor ALK1, resulting in phosphorylation of Smad1, Smad5, or Smad8, which form a complex with the co-Smad Smad4 and translocate to the nucleus to promote cartilage matrix anabolism by modifying gene expression. Meanwhile, the activated TGF- $\beta$ type II receptor ALK5 results in phosphorylation of Smad 2 or Smad3 which form a complex with the co-Smad Smad4 and translocate to the nucleus to promote cartilage matrix catabolism by modifying gene expression.

ratio from 1 to 5 over the same period of time. Clearly increased ALK1/ALK5 ratios in chondrocytes are associated with aging and OA development [110].

\section{Chondrocyte Senescence}

Chondrocytes are very unique cells that easily develop into age-related changes with aging. The chondrocytes present in the articular cartilage of an 80-year old are likely to be the very same cells as those present in a 25-year old. There is little to no cell division or cell death in normal adult articular chondrocytes [43], and there seems to be no ready supply of progenitor cells to replace dead chondrocytes if cell death does occur. The articular chondrocytes which underwent more cell divisions exhibit telomere shortening [111]. Aging itself is not associated with chondrocyte proliferation, but rather with loss of normal mitogenic response of isolated chondrocytes to growth factor stimulation [112].
There are two types of senescence: intrinsic and extrinsic. The classic replicative senescence or "intrinsic senescence" is attributed to shortened telomeres accompanied by telomere dysfunction [113]. Evidence of telomere shortening in chondrocytes from older adults has been reported [114]. However, the senescence in articular cartilage seems more relevant to the "extrinsic senescence" or stress-induced senescence, which occurs in response to telomere-damaging stimuli, including oxidative damage, activated oncogenes, and inflammation $[113,115]$ and is a much more likely mechanism for senescence in cartilage [116].

Accumulation of cells exhibiting the senescent secretory phenotype contributes to tissue aging $[115,117]$. This phenotype is characterized by increased production of cytokines including IL-6 and IL-1, matrix metalloproteinases, and growth factors such as EGF with some features in common with the OA chondrocyte phenotype. Studies have shown increased expression of MMP-3 and MMP-13 in aged cartilage $[118,119]$ as well as age-related accumulation of collagen neoepitopes representing denatured or cleaved collagen [120, 121]. It was shown that increased MMPs mediate cartilage matrix damage during aging, and collagenases and cathepsin $\mathrm{K}$ were also implicated in this process recently [122].

Other mediators of cellular senescence include TRF (telomeric repeat binding factor), XRCC5 (X-ray repair complementing defective repair in Chinese hamster cells 5), and SIRT1 (sirtuin 1). TRF1 and TRF2 are telomeric proteins that function to form and maintain telomere structure $[123,124]$. XRCC5 is involved in repairing DNA double-strand breaks [125]. SIRT1 is a negative regulator of p53 and prevents growth arrest, senescence, and apoptosis [126]. Oxidative stress in human chondrocytes induces senescence and accelerates telomere shortening [127]. After acute oxidative insult, TRF1, TRF2, XRCC5, and SIRT1 are upregulated in the early passages of human chondrocytes but induced to a less extent in late passages of chondrocytes [127]. This finding suggests that TRF proteins, XRCC5, and SIRT1 help young chondrocytes to cope with oxidative stress by preventing DNA damage accumulation and telomere shortening. Consistently, aged chondrocytes with lower induction levels of these regulatory proteins have a reduced tolerance to oxidative challenge, and accumulation of DNA damage may trigger chondrocyte senescence. Membrane protein caveolin-1 is also involved in senescence. Expression of caveolin proteins is increased in tissues of old rats [128], and overexpression of caveolin-1 leads to a senescent phenotype, likely through the $\mathrm{p} 53 / \mathrm{p} 21$ pathway [116]. In addition, angiogenic growth factor (AGF) treatment in human chondrocytes downregulated interleukin-1 $\beta$ - (IL$1 \beta$-) induced caveolin-1 expression and prevented chondrocyte replicative lifespan shortening. Inhibition of $\mathrm{p} 42 / \mathrm{p} 44$ mitogen-activated protein kinase (MAPK) and phosphoinositide 3-kinase (PI3K) abolished the effect of AGF on caveolin-1, suggesting that the AGF-mediated inhibition of $\mathrm{IL}-1 \beta$-induced chondrocyte aging is regulated, at least in part, by $\mathrm{p} 42 / 44$ MAPK and PI3K [129].

The Wnt family of secreted glycosylated proteins are linked to the development of a number of age-related pathologies such as osteoarthritis. Manipulation of Wnt signaling has the potential to impact both cellular survival and 


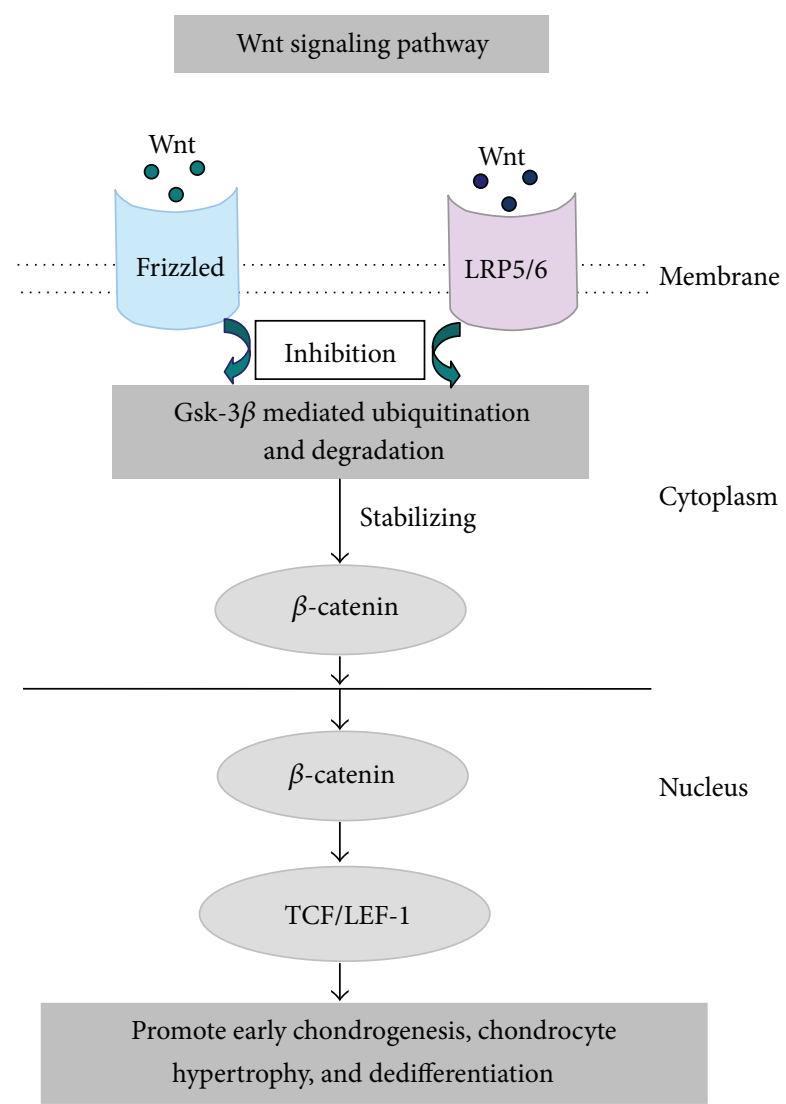

FIGURE 3: Schematic diagram showing the role of Wnt signaling in age-related changes of cartilage. Wnt could bind to Frizzled receptors and LRP5/6 coreceptors and lead to stabilization of $\beta$ catenin via inhibition of GSK-3 $\beta$ mediated ubiquitination and degradation. Then $\beta$-catenin translocated to the nucleus and bound to TCF/LEF-1 transcription factors, which can inhibit and promote early chondrogenesis as well as promote hypertrophy and chondrocyte dedifferentiation.

longevity; however, aberrant Wnt signaling can promote cell senescence [130]. Disruption of Wnt signaling has also been associated with altered joint formation, chondrogenesis, and OA [131-133]. Wnt signaling occurs through canonical $(\beta-$ catenin dependent) and noncanonical ( $\beta$-catenin independent) pathways. In canonical Wnt signaling, Wnt binding to Frizzled receptors and LRP5/6 coreceptors leads to stabilization of $\beta$-catenin via inhibition of GSK-3 $\beta$ mediated ubiquitination and degradation (Figure 3). $\beta$-catenin can then translocate to the nucleus and bind to TCF/LEF-1 transcription factors (Figure 3). OA-like changes occur in mice following both under- and overactivation of the Wnt pathway [134] (Figure 3). Canonical Wnt signaling has been reported to both inhibit and promote early chondrogenesis and to promote hypertrophy and chondrocyte dedifferentiation [135] (Figure 3). In contrast, the noncanonical pathway, through Wnt5a and Wnt5b, can promote chondrogenesis and inhibit hypertrophy [136]. This suggests that fine regulation of the Wnt pathway is essential for proper cartilage development and homeostasis. Recently, activation of the Wnt pathway was shown to inhibit IL-1-mediated MMP-13 expression in human chondrocytes. This was TCF/LEF independent and mediated through a direct interaction between NF- $\kappa \mathrm{B}$ and $\beta$ catenin, suggesting a potential protective function of Wnt in aging and OA [137]. Interestingly, HMGB2 and Wnt activity colocalize in the superficial zone of articular cartilage [138]. Age-related loss of HMGB2 and OA could also be associated with loss of Wnt activity in the superficial zone of articular cartilage, although Wnt activity is enhanced in other zones within articular cartilage, along with osteophytes and subchondral bone [138]. Understanding the impact and mechanisms underlying the imbalance of Wnt activity across the joint will provide insights into aging and OA-related cartilage degradation.

\section{Epigenetics}

There is a growing interest in the role epigenetics play in age-related conditions including OA. Epigenetic regulation of gene expression includes DNA methylation, histone acetylation and methylation, and micro-RNA (miRNA). Sirtuins are a family of NADt-dependent deacetylases that are linked to aging and more recently shown to be involved in OA through the regulation of cellular energy and metabolism [139]. The sirtuin SirT1 promotes chondrocyte survival and matrix gene expression. TNF- $\alpha$ cleaves and inactivates SirT1 and thereby contributes to reduced matrix gene expression [140]. Mice heterozygous for SirT1 $(+/-)$ with significantly decreased SirT1 expression developed premature OA-like changes at 9 months of age, which may be due to increased chondrocyte apoptosis [141].

Recent evidence [142] showed that a site within the promoter region of MMP-13 was demethylated in OA chondrocytes. It not only can make the cAMP response element bind to the promoter region but also can upregulate MMP13 expression. Histone methylation is implicated in the agedependent expression of the nuclear factor of activated $\mathrm{T}$ cells, cytoplasmic, calcineurin-dependent 1 (NFATcl) that promotes cartilage homeostasis [143]. In one study [144], miR-199a-3p and miR-193b were upregulated with age, whereas miR-320c was downregulated. These two upregulated miRNAs were found to reduce collagen and aggrecan expression in vitro, suggesting that they are antianabolic and may be involved in the age-related decrease in matrix gene expression. The development of postgenomics enabled the extensive and intensive study of the role of long noncoding RNA (lncRNA) in gene regulation [144]. So far, few studies on microRNA and lncRNA have been reported in the field of age-related OA [145]. A growing interest in this field of research may provide valuable clues to elucidate the pathogenesis of age-related OA.

\section{Conclusion}

OA-induced financial and social burdens have become more and more severe with aging of the population. Age-related changes in cartilage have been identified as critical factors in OA development. However, the underlying molecular mechanisms are not completely clarified yet, even though some 
theories have been proposed. Critical factors and signaling pathways that may play important roles in age-related changes of OA cartilage need to be further investigated. In addition, the importance of lncRNA in gene regulation is now better understood, and the potential role of lncRNAs as biological markers in diagnosis and prognosis of clinical diseases has also been considered. Studies focusing on these topics will provide more important clues for better understanding of the age-related OA.

\section{Acknowledgments}

The study was supported by Grant R01AR059142 from NIH/NIAMS and P20RR024484 from NIH/NCRR, NSFC 81071495, 81171676, and 81201435 SXNSF 2011011042. The content is solely the responsibility of the authors and does not necessarily represent the official view of the National Institutes of Health. The authors gratefully acknowledge Ericka M. Bueno, Ph.D., for help with the paper preparation and editorial services.

\section{References}

[1] J. W. J. Bijlsma, F. Berenbaum, and F. P. J. G. Lafeber, "Osteoarthritis: an update with relevance for clinical practice," The Lancet, vol. 377, no. 9783, pp. 2115-2126, 2011.

[2] T. Aigner, J. Rose, J. Martin, and J. Buckwalter, "Aging theories of primary osteoarthritis: from epidemiology to molecular biology," Rejuvenation Research, vol. 7, no. 2, pp. 134-145, 2004.

[3] D. J. Leong and H. B. Sun, "Events in articular chondrocytes with aging," Current Osteoporosis Reports, vol. 9, no. 4, pp. 196201, 2011.

[4] R. F. Loeser, "Aging processes and the development of osteoarthritis," Current Opinion in Rheumatology, vol. 25, no. 1, pp. 108113, 2013.

[5] J. A. Martin and J. A. Buckwalter, "The role of chondrocyte senescence in the pathogenesis of osteoarthritis and in limiting cartilage repair," Journal of Bone and Joint Surgery A, vol. 85, supplement 2, pp. 106-110, 2003.

[6] H. Messai, Y. Duchossoy, A. Khatib, A. Panasyuk, and D. R. Mitrovic, "Articular chondrocytes from aging rats respond poorly to insulin-like growth factor-1: an altered signaling pathway," Mechanisms of Ageing and Development, vol. 115, no. 1-2, pp. 21-37, 2000.

[7] F. J. Blanco, I. Rego, and C. Ruiz-Romero, "The role of mitochondria in osteoarthritis," Nature Reviews Rheumatology, vol. 7, no. 3, pp. 161-169, 2011.

[8] C. Huang, K. Lai, L. Hung, W. Wu, F. Liu, and L. Ho, "Advanced glycation end products cause collagen II reduction by activating Janus kinase/signal transducer and activator of transcription 3 pathway in porcine chondrocytes," Rheumatology, vol. 50, no. 8, pp. 1379-1389, 2011.

[9] T. Hugle, J. Geurts, C. Nuesch, M. Muller-Gerbl, and V. Valderrabano, "Aging and osteoarthritis: an inevitable encounter?” Journal of Aging Research, vol. 2012, Article ID 950192, 7 pages, 2012.

[10] A. C. Chen, M. M. Temple, D. M. Ng et al., "Induction of advanced glycation end products and alterations of the tensile properties of articular cartilage," Arthritis \& Rheumatism, vol. 46, no. 12, pp. 3212-3217, 2002.

[11] R. A. Bank, M. T. Bayliss, F. P. J. G. Lafeber, A. Maroudas, and J. M. Tekoppele, "Ageing and zonal variation in post-translational modification of collagen in normal human articular cartilage: the age-related increase in Non-Enzymatic Glycation affects biomechanical properties of cartilage," Biochemical Journal, vol. 330, part 1, pp. 345-351, 1998.

[12] T. Wells, C. Davidson, M. Mörgelin, J. L. E. Bird, M. T. Bayliss, and J. Dudhia, "Age-related changes in the composition, the molecular stoichiometry and the stability of proteoglycan aggregates extracted from human articular cartilage," Biochemical Journal, vol. 370, no. 1, pp. 69-79, 2003.

[13] J. DeGroot, N. Verzijl, R. A. Bank et al., "Age-related decrease in proteoglycan synthesis of human articular chondrocytes: the role of nonenzymatic glycation," Arthritis \& Rheumatism, vol. 42, no. 5, pp. 1003-1109, 1999.

[14] R. F. Loeser, S. R. Goldring, C. R. Scanzello, and M. B. Goldring, "Osteoarthritis: a disease of the joint as an organ," Arthritis \& Rheumatism, vol. 64, no. 6, pp. 1697-1707, 2012.

[15] N. Arden and M. C. Nevitt, "Osteoarthritis: epidemiology," Best Practice and Research, vol. 20, no. 1, pp. 3-25, 2006.

[16] R. C. Lawrence, D. T. Felson, C. G. Helmick et al., "Estimates of the prevalence of arthritis and other rheumatic conditions in the United States. Part II," Arthritis \& Rheumatism, vol. 58, no. 1, pp. 26-35, 2008.

[17] "Prevalence of doctor-diagnosed arthritis and arthritis-attributable activity limitation-United States, 2007-2009," Morbidity and Mortality Weekly Report, vol. 59, no. 39, pp. 1261-1265.

[18] C. De Bari, T. B. Kurth, and A. Augello, "Mesenchymal stem cells from development to postnatal joint homeostasis, aging, and disease," Birth Defects Research C, vol. 90, no. 4, pp. 257$271,2010$.

[19] M. E. Miller, W. Jack Rejeski, S. P. Messier, and R. F. Loeser, "Modifiers of change in physical functioning in older adults with knee pain: the Observational Arthritis Study in Seniors (OASIS)," Arthritis Care and Research, vol. 45, no. 4, pp. 331-339, 2001.

[20] J. A. Buckwalter, C. Saltzman, and T. Brown, "The impact of osteoarthritis: implications for research," Clinical Orthopaedics and Related Research, vol. 427, pp. S6-S15, 2004.

[21] R. J. Goekoop, M. Kloppenburg, H. M. Kroon et al., "Determinants of absence of osteoarthritis in old age," Scandinavian Journal of Rheumatology, vol. 40, no. 1, pp. 68-73, 2011.

[22] J. M. Jordan, C. G. Helmick, J. B. Renner et al., "Prevalence of knee symptoms and radiographic and symptomatic knee osteoarthritis in African Americans and Caucasians: the Johnston County Osteoarthritis Project," Journal of Rheumatology, vol. 34, no. 1, pp. 172-180, 2007.

[23] J. M. Jordan, C. G. Helmick, J. B. Renner et al., "Prevalence of hip symptoms and radiographic and symptomatic hip osteoarthritis in African Americans and Caucasians: the Johnston County osteoarthritis project," Journal of Rheumatology, vol. 36, no. 4, pp. 809-815, 2009.

[24] N. K. Arden, N. E. Lane, N. Parimi et al., "Defining incident radiographic hip osteoarthritis for epidemiologic studies in women," Arthritis \& Rheumatism, vol. 60, no. 4, pp. 1052-1059, 2009. 
[25] Y. Zhang, J. Niu, M. Kelly-Hayes, C. E. Chaisson, P. Aliabadi, and D. T. Felson, "Prevalence of symptomatic hand osteoarthritis and its impact on functional status among the elderly: the framingham study," American Journal of Epidemiology, vol. 156, no. 11, pp. 1021-1027, 2002.

[26] L. Murphy, T. A. Schwartz, C. G. Helmick et al., "Lifetime risk of symptomatic knee osteoarthritis," Arthritis Care and Research, vol. 59, no. 9, pp. 1207-1213, 2008.

[27] T. Neogi and Y. Zhang, "Epidemiology of osteoarthritis," Rheumatic Disease Clinics of North America, vol. 39, no. 1, pp. 1-19, 2010.

[28] D. T. Felson, N. N. Couropmitree, C. E. Chaisson et al., "Evidence for a Mendelian gene in a segregation analysis of generalized radiographic osteoarthritis: the Framingham study," Arthritis \& Rheumatism, vol. 41, no. 6, pp. 1064-1071, 1998.

[29] A. Palotie, P. Vaisanen, J. Ott et al., "Predisposition to familial osteoarthrosis linked to type II collagen gene," The Lancet, vol. 1, no. 8644, pp. 924-927, 1989.

[30] E. Evangelou, A. M. Valdes, H. J. Kerkhof et al., "Meta-analysis of genome-wide association studies confirms a susceptibility locus for knee osteoarthritis on chromosome 7q22," Annals of the Rheumatic Diseases, vol. 70, no. 2, pp. 349-355, 2011.

[31] A. M. Valdes, E. Evangelou, H. J. M. Kerkhof et al., “The GDF5 rs143383 polymorphism is associated with osteoarthritis of the knee with genome-wide statistical significance," Annals of the Rheumatic Diseases, vol. 70, no. 5, pp. 873-875, 2011.

[32] A. G. Day-Williams, L. Southam, K. Panoutsopoulou et al., "A variant in MCF2L is associated with osteoarthritis," The American Journal of Human Genetics, vol. 89, no. 3, pp. 446450, 2011.

[33] J. B. J. van Meurs, A. G. Uitterlinden, L. Stolk et al., "A functional polymorphism in the catechol-O-methyltransferase gene is associated with osteoarthritis-related pain," Arthritis \& Rheumatism, vol. 60, no. 2, pp. 628-629, 2009.

[34] A. M. Valdes, G. De Wilde, S. A. Doherty et al., "The Ile585Val TRPV1 variant is involved in risk of painful knee osteoarthritis," Annals of the Rheumatic Diseases, vol. 70, no. 9, pp. 1556-1561, 2011.

[35] A. M. Malfait, A. B. Seymour, F. Gao et al., "A role for PACE4 in osteoarthritis pain: evidence from human genetic association and null mutant phenotype," Annals of the Rheumatic Diseases, vol. 71, no. 6, pp. 1042-1048, 2012.

[36] J. A. Martin and J. A. Buckwalter, "Aging, articular cartilage chondrocyte senescence and osteoarthritis," Biogerontology, vol. 3, no. 5, pp. 257-264, 2002.

[37] J. A. Buckwalter, P. J. Roughley, and L. C. Rosenberg, "Agerelated changes in cartilage proteoglycans: quantitative electron microscopic studies," Microscopy Research and Technique, vol. 28, no. 5, pp. 398-408, 1994.

[38] M. C. Bolton, J. Dudhia, and M. T. Bayliss, "Age-related changes in the synthesis of link protein and aggrecan in human articular cartilage: implications for aggregate stability," Biochemical Journal, vol. 337, part 1, pp. 77-82, 1999.

[39] W. E. Horton Jr., L. Feng, and C. Adams, "Chondrocyte apoptosis in development, aging and disease," Matrix Biology, vol. 17, no. 2, pp. 107-115, 1998.

[40] T. Aigner, H. A. Kim, and H. I. Roach, "Apoptosis in osteoarthritis," Rheumatic Disease Clinics of North America, vol. 30, no. 3, pp. 639-653, 2004.
[41] K. Kühn, D. D. D’Lima, S. Hashimoto, and M. Lotz, "Cell death in cartilage," Osteoarthritis and Cartilage, vol. 12, no. 1, pp. 1-16, 2004.

[42] E. Vignon, M. Arlot, L. M. Patricot, and G. Vignon, "The cell density of human femoral head cartilage," Clinical Orthopaedics and Related Research, vol. 121, pp. 303-308, 1976.

[43] T. Aigner, M. Hemmel, D. Neureiter et al., "Apoptotic cell death is not a widespread phenomenon in normal aging and osteoarthritis human articular knee cartilage: a study of proliferation, programmed cell death (apoptosis), and viability of chondrocytes in normal and osteoarthritic human knee cartilage," Arthritis \& Rheumatism, vol. 44, no. 6, pp. 1304-1312, 2001.

[44] C. S. Adams and W. E. Horton Jr., "Chondrocyte apoptosis increases with age in the articular cartilage of adult animals," Anatomical Record, vol. 250, no. 4, pp. 418-425, 1998.

[45] N. Taniguchi, B. Caramés, L. Ronfani et al., "Aging-related loss of the chromatin protein HMGB2 in articular cartilage is linked to reduced cellularity and osteoarthritis," Proceedings of the National Academy of Sciences of the United States of America, vol. 106, no. 4, pp. 1181-1186, 2009.

[46] M. Del Carlo Jr. and R. F. Loeser, "Increased oxidative stress with aging reduces chondrocyte survival: correlation with intracellular glutathione levels," Arthritis \& Rheumatism, vol. 48, no. 12, pp. 3419-3430, 2003.

[47] L. A. Fortier, J. U. Barker, E. J. Strauss, T. M. McCarrel, and B. J. Cole, "The role of growth factors in cartilage repair," Clinical Orthopaedics and Related Research, vol. 469, no. 10, pp. 27062715, 2011.

[48] R. F. Loeser, G. Shanker, C. S. Carlson, J. F. Gardin, B. J. Shelton, and W. E. Sonntag, "Reduction in the chondrocyte response to insulin-like growth factor 1 in aging and osteoarthritis: studies in a non-human primate model of naturally occurring disease," Arthritis \& Rheumatism, vol. 43, no. 9, pp. 2110-2120, 2000.

[49] J. A. Martin, S. M. Ellerbroek, and J. A. Buckwalter, "Age-related decline in chondrocyte response to insulin-like growth factor-I: the role of growth factor binding proteins," Journal of Orthopaedic Research, vol. 15, no. 4, pp. 491-498, 1997.

[50] S. Chubinskaya, B. Kumar, C. Merrihew, K. Heretis, D. C. Rueger, and K. E. Kuettner, "Age-related changes in cartilage endogenous osteogenic protein-1 (OP-1)," Biochimica et Biophysica Acta, vol. 1588, no. 2, pp. 126-134, 2002.

[51] E. N. B. Davidson, A. Scharstuhl, E. L. Vitters, P. M. van der Kraan, and W. B. van den Berg, "Reduced transforming growth factor-beta signaling in cartilage of old mice: role in impaired repair capacity," Arthritis Research \& Therapy, vol. 7, no. 6, pp. R1338-R1347, 2005.

[52] A. Scharstuhl, H. M. van Beuningen, E. L. Vitters, P. M. van der Kraan, and W. B. van den Berg, "Loss of transforming growth factor counteraction on interleukin 1 mediated effects in cartilage of old mice," Annals of the Rheumatic Diseases, vol. 61, no. 12, pp. 1095-1098, 2002.

[53] H. M. van Beuningen, P. M. van der Kraan, O. J. Arntz, and W. B. van den Berg, "Transforming growth factor- $\beta 1$ stimulates articular chondrocyte proteoglycan synthesis and induces osteophyte formation in the murine knee joint," Laboratory Investigation, vol. 71, no. 2, pp. 279-290, 1994.

[54] P. M. van der Kraan, E. N. Davidson, and W. B. van den Berg, "A role for age-related changes in TGF $\beta$ signaling in aberrant chondrocyte differentiation and osteoarthritis," Arthritis Research \& Therapy, vol. 12, no. 1, article 201, 2010. 
[55] S. Dore, J.-P. Pelletier, J. A. DiBattista, G. Tardif, P. Brazeau, and J. Martel- Pelletier, "Human osteoarthritic chondrocytes possess an increased number of insulin- like growth factor 1 binding sites but are unresponsive to its stimulation: possible role of IGF-1-binding proteins," Arthritis \& Rheumatism, vol. 37, no. 2, pp. 253-263, 1994.

[56] L. J. Sandell and T. Aigner, "Articular cartilage and changes in arthritis. An introduction: cell biology of osteoarthritis," Arthritis Research, vol. 3, no. 2, pp. 107-113, 2001.

[57] N. Fukui, Y. Ikeda, T. Ohnuki et al., "Regional differences in chondrocyte metabolism in osteoarthritis: a detailed analysis by laser capture microdissection," Arthritis \& Rheumatism, vol. 58, no. 1, pp. 154-163, 2008.

[58] D. M. Visco, B. Johnstone, M. A. Hill, G. A. Jolly, and B. Caterson, "Immunohistochemical analysis of 3-B-3(-) and 7D-4 epitope expression in canine osteoarthritis," Arthritis \& Rheumatism, vol. 36, no. 12, pp. 1718-1725, 1993.

[59] H. B. Sun, "Mechanical loading, cartilage degradation, and arthritis," Annals of the New York Academy of Sciences, vol. 1211, pp. 37-50, 2010.

[60] R. F. Loeser, "Age-related changes in the musculoskeletal system and the development of osteoarthritis," Clinics in Geriatric Medicine, vol. 26, no. 3, pp. 371-386, 2010.

[61] J. Uribarri, S. Woodruff, S. Goodman et al., "Advanced glycation end products in foods and a practical guide to their reduction in the diet," Journal of the American Dietetic Association, vol. 110, no. 6, pp. 911.e12-916.e12, 2010.

[62] P. Ulrich and A. Cerami, "Protein glycation, diabetes, and aging," Recent Progress in Hormone Research, vol. 56, pp. 1-21, 2001.

[63] S.-S. Nah, I.-Y. Choi, C. K. Lee et al., "Effects of advanced glycation end products on the expression of COX-2, PGE2 and NO in human osteoarthritic chondrocytes," Rheumatology, vol. 47, no. 4, pp. 425-431, 2008.

[64] S. Nah, I. Choi, B. Yoo, Y. G. Kim, H. Moon, and C. Lee, "Advanced glycation end products increases matrix metalloproteinase-1, -3 , and -13 , and TNF- $\alpha$ in human osteoarthritic chondrocytes," FEBS Letters, vol. 581, no. 9, pp. 1928-1932, 2007.

[65] N. Verzijl, J. DeGroot, Z. C. Ben et al., "Crosslinking by advanced glycation end products increases the stiffness of the collagen network in human articular cartilage: a possible mechanism through which age is a risk factor for osteoarthritis," Arthritis \& Rheumatism, vol. 46, no. 1, pp. 114-123, 2002.

[66] K. Yang, X. Q. Wang, Y. S. He et al., "Advanced glycation end products induce chemokine/cytokine production via activation of p38 pathway and inhibit proliferation and migration of bone marrow mesenchymal stem cells," Cardiovascular Diabetology, vol. 9, article 66, 2010.

[67] E. L. M. Guimarães, C. Empsen, A. Geerts, and L. A. van Grunsven, "Advanced glycation end products induce production of reactive oxygen species via the activation of NADPH oxidase in murine hepatic stellate cells," Journal of Hepatology, vol. 52, no. 3, pp. 389-397, 2010.

[68] A. Whaley-Connell, P. A. McCullough, and J. R. Sowers, "The role of oxidative stress in the metabolic syndrome," Reviews in Cardiovascular Medicine, vol. 12, no. 1, pp. 21-29, 2011.

[69] R. Studer, D. Jaffurs, M. Stefanovic-Racic, P. D. Robbins, and C. H. Evans, "Nitric oxide in osteoarthritis," Osteoarthritis and Cartilage, vol. 7, no. 4, pp. 377-379, 1999.
[70] T. S. Hiran, P. J. Moulton, and J. T. Hancock, "Detection of superoxide and NAPDH oxidase in porcine articular chondrocytes," Free Radical Biology and Medicine, vol. 23, no. 5, pp. 736-743, 1997.

[71] M. L. Tiku, R. Shah, and G. T. Allison, "Evidence linking chondrocyte lipid peroxidation to cartilage matrix protein degradation: possible role in cartilage aging and the pathogenesis of osteoarthritis," The Journal of Biological Chemistry, vol. 275, no. 26, pp. 20069-20076, 2000.

[72] N. Jallali, H. Ridha, C. Thrasivoulou, C. Underwood, P. E. M. Butler, and T. Cowen, "Vulnerability to ROS-induced cell death in ageing articular cartilage: the role of antioxidant enzyme activity," Osteoarthritis and Cartilage, vol. 13, no. 7, pp. 614-622, 2005.

[73] C. M. Davies, F. Guilak, J. B. Weinberg, and B. Fermor, "Reactive nitrogen and oxygen species in interleukin-1-mediated DNA damage associated with osteoarthritis," Osteoarthritis and Cartilage, vol. 16, no. 5, pp. 624-630, 2008.

[74] K. Yudoh, V. T. Nguyen, H. Nakamura, K. Hongo-Masuko, T. Kato, and K. Nishioka, "Potential involvement of oxidative stress in cartilage senescence and development of osteoarthritis: oxidative stress induces chondrocyte telomere instability and downregulation of chondrocyte function," Arthritis Research \& Therapy, vol. 7, no. 2, pp. R380-R391, 2005.

[75] S. Nakagawa, Y. Arai, O. Mazda et al., "N-acetylcysteine prevents nitric oxide-induced chondrocyte apoptosis and cartilage degeneration in an experimental model of osteoarthritis," Journal of Orthopaedic Research, vol. 28, no. 2, pp. 156-163, 2010.

[76] K. K. Nelson and J. A. Melendez, "Mitochondrial redox control of matrix metalloproteinases," Free Radical Biology and Medicine, vol. 37, no. 6, pp. 768-784, 2004.

[77] W. Goodwin, D. McCabe, E. Sauter et al., "Rotenone prevents impact-induced chondrocyte death," Journal of Orthopaedic Research, vol. 28, no. 8, pp. 1057-1063, 2010.

[78] P. J. Marie and M. Kassem, "Extrinsic mechanisms involved in age-related defective bone formation," Journal of Clinical Endocrinology and Metabolism, vol. 96, no. 3, pp. 600-609, 2011.

[79] R. Shirazi and A. Shirazi-Adl, "Computational biomechanics of articular cartilage of human knee joint: effect of osteochondral defects," Journal of Biomechanics, vol. 42, no. 15, pp. 2458-2465, 2009.

[80] J. E. Stevens, S. Binder-Macleod, and L. Snyder-Mackler, "Characterization of the human quadriceps muscle in active elders," Archives of Physical Medicine and Rehabilitation, vol. 82, no. 7, pp. 973-978, 2001.

[81] W. Yin, J. Park, and R. F. Loeser, "Oxidative stress inhibits insulin-like growth factor-I induction of chondrocyte proteoglycan synthesis through differential regulation of phosphatidylinositol 3-kinase-Akt and MEK-ERK MAPK signaling pathways," The Journal of Biological Chemistry, vol. 284, no. 46, pp. 31972-31981, 2009.

[82] P. Krejci, J. Prochazkova, J. Smutny et al., "FGFR3 signaling induces a reversible senescence phenotype in chondrocytes similar to oncogene-induced premature senescence," Bone, vol. 47, no. 1, pp. 102-110, 2010.

[83] S. Zushi, M. Akagi, H. Kishimoto, T. Teramura, T. Sawamura, and C. Hamanishi, "Induction of bovine articular chondrocyte senescence with oxidized low-density lipoprotein through lectin-like oxidized low-density lipoprotein receptor 1," Arthritis \& Rheumatism, vol. 60, no. 10, pp. 3007-3016, 2009. 
[84] H. Kishimoto, M. Akagi, S. Zushi et al., "Induction of hypertrophic chondrocyte-like phenotypes by oxidized LDL in cultured bovine articular chondrocytes through increase in oxidative stress," Osteoarthritis and Cartilage, vol. 18, no. 10, pp. 1284-1290, 2010.

[85] J. L. Scott, C. Gabrielides, R. K. Davidson et al., "Superoxide dismutase downregulation in osteoarthritis progression and end-stage disease," Annals of the Rheumatic Diseases, vol. 69, no. 8, pp. 1502-1510, 2010.

[86] I. Rego-Pérez, M. Fernández-Moreno, M. Deberg et al., "Mitochondrial DNA haplogroups and serum levels of proteolytic enzymes in patients with osteoarthritis," Annals of the Rheumatic Diseases, vol. 70, no. 4, pp. 646-652, 2011.

[87] S. M. Botter, M. Zar, G. J. V. M. van Osch et al., "Analysis of osteoarthritis in a mouse model of the progeroid human DNA repair syndrome trichothiodystrophy," Age, vol. 33, no. 3, pp. 247-260, 2011.

[88] M. Hudelmaier, C. Glaser, J. Hohe et al., "Age-related changes in the morphology and deformational behavior of knee joint cartilage," Arthritis \& Rheumatism, vol. 44, no. 11, pp. 25562561, 2001.

[89] C. Ding, F. Cicuttini, F. Scott, H. Cooley, and G. Jones, "Association between age and knee structural change: a cross sectional MRI based study," Annals of the Rheumatic Diseases, vol. 64, no. 4, pp. 549-555, 2005.

[90] N. Verzijl, J. DeGroot, S. R. Thorpe et al., "Effect of collagen turnover on the accumulation of advanced glycation end products," The Journal of Biological Chemistry, vol. 275, no. 50, pp. 39027-39031, 2000.

[91] J. Dudhia, C. M. Davidson, T. M. Wells, D. H. Vynios, T. E. Hardingham, and M. T. Bayliss, "Age-related changes in the content of the C-terminal region of aggrecan in human articular cartilage," Biochemical Journal, vol. 313, part 3, pp. 933-940, 1996.

[92] M. T. Bayliss, D. Osborne, S. Woodhouse, and C. Davidson, "Sulfation of chondroitin sulfate in human articular cartilage: the effect of age, topographical position, and zone of cartilage on tissue composition," The Journal of Biological Chemistry, vol. 274, no. 22, pp. 15892-15900, 1999.

[93] G. Grushko, R. Schneiderman, and A. Maroudas, "Some biochemical and biophysical parameters for the study of the pathogenesis of osteoarthritis: a comparison between the processes of ageing and degeneration in human hip cartilage," Connective Tissue Research, vol. 19, no. 2-4, pp. 149-176, 1989.

[94] A. Maroudas, M. T. Bayliss, N. Uchitel-Kaushansky, R. Schneiderman, and E. Gilav, "Aggrecan turnover in human articular cartilage: use of aspartic acid racemization as a marker of molecular age," Archives of Biochemistry and Biophysics, vol. 350, no. 1, pp. 61-71, 1998.

[95] C. B. Little and S. Zaki, "What constitutes an "animal model of osteoarthritis" - the need for consensus?" Osteoarthritis and Cartilage, vol. 20, no. 4, pp. 261-267, 2012.

[96] G. Valverde-Franco, J. S. Binette, W. Li et al., "Defects in articular cartilage metabolism and early arthritis in fibroblast growth factor receptor 3 deficient mice," Human Molecular Genetics, vol. 15, no. 11, pp. 1783-1792, 2006.

[97] T. Weng, L. Yi, J. Huang et al., "Genetic inhibition of fibroblast growth factor receptor 1 in knee cartilage attenuates the degeneration of articular cartilage in adult mice," Arthritis \& Rheumatism, vol. 64, no. 12, pp. 3982-3992, 2012.
[98] D. A. Lawrence, "Latent-TGF- $\beta$ : an overview," Molecular and Cellular Biochemistry, vol. 219, no. 1-2, pp. 163-170, 2001.

[99] H. König, D. Kögel, A. Rami, and J. H. M. Prehn, “TGF- $\beta 1$ activates two distinct type I receptors in neurons: implications for neuronal NF- $\kappa$ B signaling," Journal of Cell Biology, vol. 168, no. 7, pp. 1077-1086, 2005.

[100] K. W. Finnson, W. L. Parker, P. ten Dijke, M. Thorikay, and A. Philip, "ALK1 opposes ALK5/Smad3 signaling and expression of extracellular matrix components in human chondrocytes," Journal of Bone and Mineral Research, vol. 23, no. 6, pp. 896906, 2008.

[101] M. Goumans, G. Valdimarsdottir, S. Itoh et al., "Activin receptor-like kinase $(\mathrm{ALK}) 1$ is an antagonistic mediator of lateral TGF $\beta /$ ALK5 signaling," Molecular Cell, vol. 12, no. 4, pp. 817-828, 2003.

[102] X. Wu, J. Ma, J. Han, N. Wang, and Y. Chen, "Distinct regulation of gene expression in human endothelial cells by TGF- $\beta$ and its receptors," Microvascular Research, vol. 71, no. 1, pp. 12-19, 2006.

[103] T. Seki, K. Hong, and S. P. Oh, "Nonoverlapping expression patterns of ALK1 and ALK5 reveal distinct roles of each receptor in vascular development," Laboratory Investigation, vol. 86, no. 2, pp. 116-129, 2006.

[104] M. Goumans, G. Valdimarsdottir, S. Itoh, A. Rosendahl, P. Sideras, and P. Ten Dijke, "Balancing the activation state of the endothelium via two distinct TGF- $\beta$ type I receptors," The EMBO Journal, vol. 21, no. 7, pp. 1743-1753, 2002.

[105] Y. E. Zhang, "Non-Smad pathways in TGF- $\beta$ signaling," Cell Research, vol. 19, no. 1, pp. 128-139, 2009.

[106] A. Sorrentino, N. Thakur, S. Grimsby et al., “The type I TGF- $\beta$ receptor engages TRAF6 to activate TAK1 in a receptor kinaseindependent manner," Nature Cell Biology, vol. 10, no. 10, pp. 1199-1207, 2008.

[107] P. M. van der Kraan, M. Goumans, E. B. Davidson, and P. ten Dijke, "Age-dependent alteration of TGF- $\beta$ signalling in osteoarthritis," Cell and Tissue Research, vol. 347, no. 1, pp. 257265, 2012.

[108] D. Yan, D. Chen, S. M. Cool et al., "Fibroblast growth factor receptor 1 is principally responsible for fibroblast growth factor 2-induced catabolic activities in human articular chondrocytes," Arthritis Research \& Therapy, vol. 13, no. 4, article R130, 2011.

[109] E. N. Davidson, E. L. Vitters, P. M. van der Kraan, and W. B. van den Berg, "Expression of transforming growth factor- $\beta$ (TGF $\beta$ ) and the TGF $\beta$ signalling molecule SMAD-2P in spontaneous and instability-induced osteoarthritis: role in cartilage degradation, chondrogenesis and osteophyte formation," Annals of the Rheumatic Diseases, vol. 65, no. 11, pp. 1414-1421, 2006.

[110] E. N. Davidson, D. F. G. Remst, E. L. Vitters et al., "Increase in ALK1/ALK5 ratio as a cause for elevated MMP-13 expression in osteoarthritis in humans and mice," Journal of Immunology, vol. 182, no. 12, pp. 7937-7945, 2009.

[111] D. Parsch, T. H. Brümmendorf, W. Richter, and J. Fellenberg, "Replicative aging of human articular chondrocytes during ex vivo expansion," Arthritis \& Rheumatism, vol. 46, no. 11, pp. 2911-2916, 2002.

[112] P. Guerne, F. Blanco, A. Kaelin, A. Desgeorges, and M. Lotz, "Growth factor responsiveness of human articular chondrocytes in aging and development," Arthritis \& Rheumatism, vol. 38, no. 7, pp. 960-968, 1995. 
[113] K. Itahana, J. Campisi, and G. P. Dimri, "Mechanisms of cellular senescence in human and mouse cells," Biogerontology, vol. 5, no. 1, pp. 1-10, 2004.

[114] J. A. Martin and J. A. Buckwalter, "Telomere erosion and senescence in human articular cartilage chondrocytes," Journals of Gerontology A, vol. 56, no. 4, pp. B172-B179, 2001.

[115] J. Campisi, "Senescent cells, tumor suppression, and organismal aging: good citizens, bad neighbors," Cell, vol. 120, no. 4, pp. 513522, 2005.

[116] S. Dai, Z. Shan, H. Nakamura et al., "Catabolic stress induces features of chondrocyte senescence through overexpression of caveolin 1: possible involvement of caveolin 1-induced downregulation of articular chondrocytes in the pathogenesis of osteoarthritis," Arthritis \& Rheumatism, vol. 54, no. 3, pp. 818831, 2006.

[117] J. Campisi and F. D. di Fagagna, "Cellular senescence: when bad things happen to good cells," Nature Reviews Molecular Cell Biology, vol. 8, no. 9, pp. 729-740, 2007.

[118] W. Wu, R. C. Billinghurst, I. Pidoux et al., "Sites of collagenase cleavage and denaturation of type II collagen in aging and osteoarthritic articular cartilage and their relationship to the distribution of matrix metalloproteinase 1 and matrix metalloproteinase 13," Arthritis \& Rheumatism, vol. 46, no. 8, pp. 20872094, 2002.

[119] M. Attur, A. Ben-Artzi, Q. Yang et al., "Perturbation of nuclear lamin A causes cell death in chondrocytes," Arthritis \& Rheumatism, vol. 64, no. 6, pp. 1940-1949, 2012.

[120] A. P. Hollander, I. Pidoux, A. Reiner, C. Rorabeck, R. Bourne, and A. R. Poole, "Damage to type II collagen in aging and osteoarthritis starts at the articular surface, originates around chondrocytes, and extends into the cartilage with progressive degeneration," Journal of Clinical Investigation, vol. 96, no. 6, pp. 2859-2869, 1995.

[121] M. Aurich, A. R. Poole, A. Reiner et al., "Matrix homeostasis in aging normal human ankle cartilage," Arthritis \& Rheumatism, vol. 46, no. 11, pp. 2903-2910, 2002.

[122] V. M. Dejica, J. S. Mort, S. Laverty et al., "Increased type II collagen cleavage by cathepsin $\mathrm{K}$ and collagenase activities with aging and osteoarthritis in human articular cartilage," Arthritis Research \& Therapy, vol. 14, no. 3, p. R113, 2012.

[123] H. Xin, D. Liu, and Z. Songyang, "The telosome/shelterin complex and its functions," Genome Biology, vol. 9, no. 9, p. 232, 2008.

[124] W. Palm and T. de Lange, "How shelterin protects mammalian telomeres," Annual Review of Genetics, vol. 42, pp. 301-334, 2008.

[125] J. Thacker and M. Z. Zdzienicka, “The XRCC genes: expanding roles in DNA double-strand break repair," DNA Repair, vol. 3, no. 8-9, pp. 1081-1090, 2004.

[126] L. Guarente, "Diverse and dynamic functions of the Sir silencing complex," Nature Genetics, vol. 23, no. 3, pp. 281-285, 1999.

[127] A. Brandl, A. Hartmann, V. Bechmann, B. Graf, M. Nerlich, and P. Angele, "Oxidative stress induces senescence in chondrocytes," Journal of Orthopaedic Research, vol. 29, no. 7, pp. 11141120, 2011.

[128] W. Park, J. Park, K. Cho et al., "Up-regulation of caveolin attenuates epidermal growth factor signaling in senescent cells," The Journal of Biological Chemistry, vol. 275, no. 27, pp. 2084720852, 2000.
[129] K. Yudoh, Y. Shi, and R. Karasawa, "Angiogenic growth factors inhibit chondrocyte ageing in osteoarthritis: potential involvement of catabolic stress-induced overexpression of caveolin-1 in cellular ageing," International Journal of Rheumatic Diseases, vol. 12, no. 2, pp. 90-99, 2009.

[130] K. Maiese, F. Li, Z. Z. Chong, and Y. C. Shang, "The Wnt signaling pathway: aging gracefully as a protectionist?" Pharmacology and Therapeutics, vol. 118, no. 1, pp. 58-81, 2008.

[131] F. Dell'Accio, C. De Bari, N. M. Eltawil, P. Vanhummelen, and C. Pitzalis, "Identification of the molecular response of articular cartilage to injury, by microarray screening: Wnt-16 expression and signaling after injury and in osteoarthritis," Arthritis of Rheumatism, vol. 58, no. 5, pp. 1410-1421, 2008.

[132] J. C. Leijten, J. Emons, C. Sticht et al., "Gremlin 1, frizzledrelated protein, and Dkk-1 are key regulators of human articular cartilage homeostasis," Arthritis \& Rheumatism, vol. 64, no. 10, pp. 3302-3312, 2012.

[133] K. A. Staines, V. E. Macrae, and C. Farquharson, "Cartilage development and degeneration: a Wnt Wnt situation," Cell Biochemistry and Function, vol. 30, no. 8, pp. 633-642, 2012.

[134] M. Zhu, D. Tang, Q. Wu et al., "Activation of $\beta$-catenin signaling in articular chondrocytes leads to osteoarthritis-like phenotype in adult $\beta$-catenin conditional activation mice," Journal of Bone and Mineral Research, vol. 24, no. 1, pp. 12-21, 2009.

[135] S. Hwang, S. Yu, S. Lee, and J. Chun, "Wnt-3a regulates chondrocyte differentiation via c-Jun/AP-1 pathway," FEBS Letters, vol. 579, no. 21, pp. 4837-4842, 2005.

[136] E. W. Bradley and M. H. Drissi, "Wnt5b regulates mesenchymal cell aggregation and chondrocyte differentiation through the planar cell polarity pathway," Journal of Cellular Physiology, vol. 226, no. 6, pp. 1683-1693, 2011.

[137] B. Ma, C. A. van Blitterswijk, and M. Karperien, "A Wnt/betacatenin negative feedback loop inhibits interleukin-1-induced matrix metalloproteinase expression in human articular chondrocytes," Arthritis \& Rheumatism, vol. 64, no. 8, pp. 2589$2600,2012$.

[138] N. Taniguchi, B. Caramés, Y. Kawakami, B. A. Amendt, S. Komiya, and M. Lotz, "Chromatin protein HMGB2 regulates articular cartilage surface maintenance via $\beta$-catenin pathway," Proceedings of the National Academy of Sciences of the United States of America, vol. 106, no. 39, pp. 16817-16822, 2009.

[139] O. Gabay and C. Sanchez, "Epigenetics, sirtuins and osteoarthritis," Joint Bone Spine, vol. 79, no. 6, pp. 570-573, 2012.

[140] M. Dvir-Ginzberg, V. Gagarina, E. J. Lee, R. Booth, O. Gabay, and D. J. Hall, "Tumor necrosis factor $\alpha$-mediated cleavage and inactivation of sirT1 in human osteoarthritic chondrocytes," Arthritis \& Rheumatism, vol. 63, no. 8, pp. 2363-2373, 2011.

[141] O. Gabay, H. Oppenheimer, H. Meir, K. Zaal, C. Sanchez, and M. Dvir-Ginzberg, "Increased apoptotic chondrocytes in articular cartilage from adult heterozygous SirT1 mice," Annals of the Rheumatic Diseases, vol. 71, no. 4, pp. 613-616, 2012.

[142] C. Bui, M. J. Barter, J. L. Scott et al., "cAMP response elementbinding (CREB) recruitment following a specific CpG demethylation leads to the elevated expression of the matrix metalloproteinase 13 in human articular chondrocytes and osteoarthritis," The FASEB Journal, vol. 26, no. 7, pp. 3000-3011, 2012.

[143] M. Rodova, Q. Lu, Y. Li et al., "Nfatl regulates adult articular chondrocyte function through its age-dependent expression 
mediated by epigenetic histone methylation," Journal of Bone and Mineral Research, vol. 26, no. 8, pp. 1974-1986, 2011.

[144] E. Steck, S. Boeuf, J. Gabler et al., "Regulation of H19 and its encoded microRNA-675 in osteoarthritis and under anabolic and catabolic in vitro conditions," Journal of Molecular Medicine, vol. 90, no. 10, pp. 1185-1195, 2012.

[145] T. Ukai, M. Sato, H. Akutsu, A. Umezawa, and J. Mochida, "MicroRNA-199a-3p, microRNA-193b, and microRNA-320c are correlated to aging and regulate human cartilage metabolism," Journal of Orthopaedic Research, vol. 30, no. 12, pp. 1915-1922, 2012. 


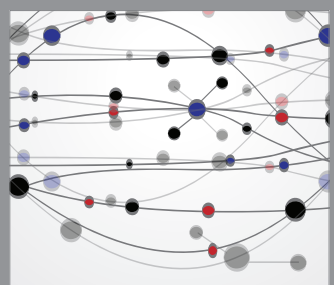

The Scientific World Journal
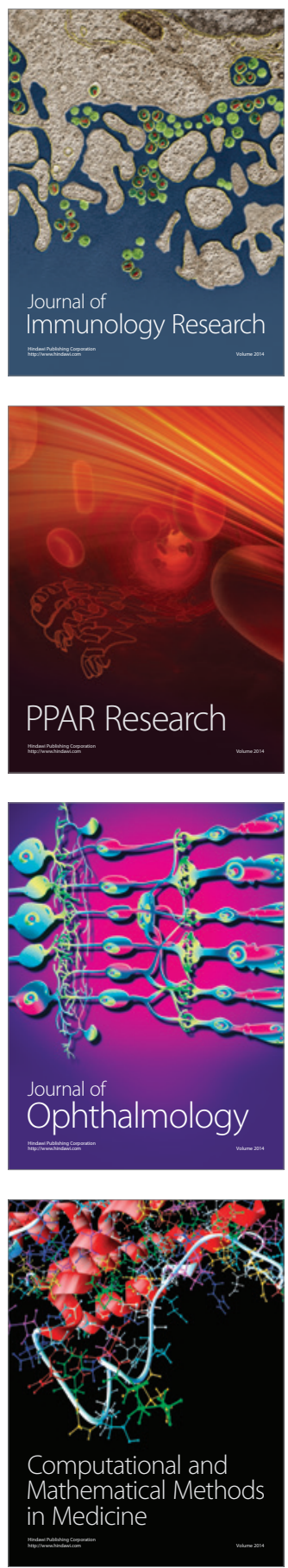

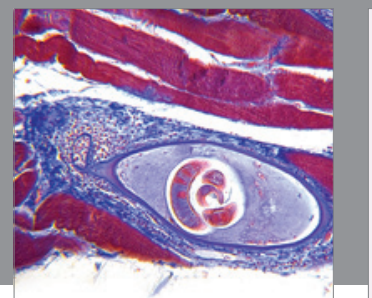

Gastroenterology

Research and Practice
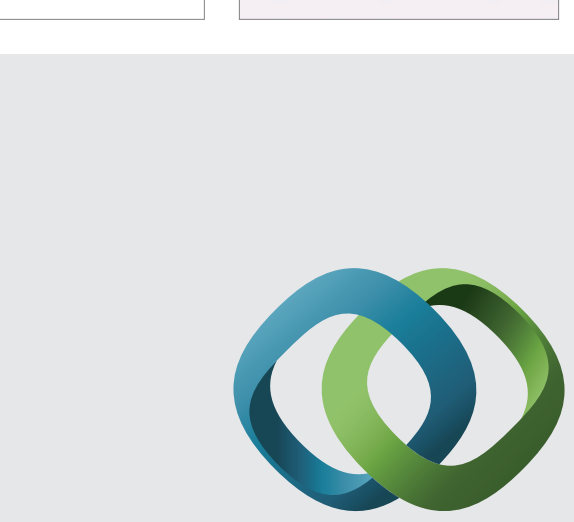

\section{Hindawi}

Submit your manuscripts at

http://www.hindawi.com
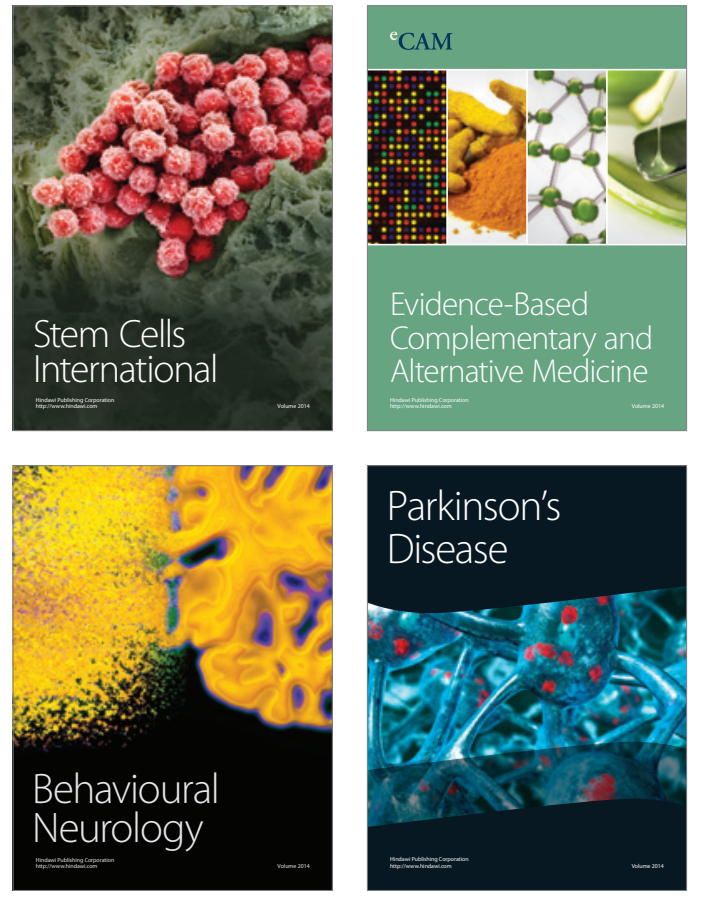
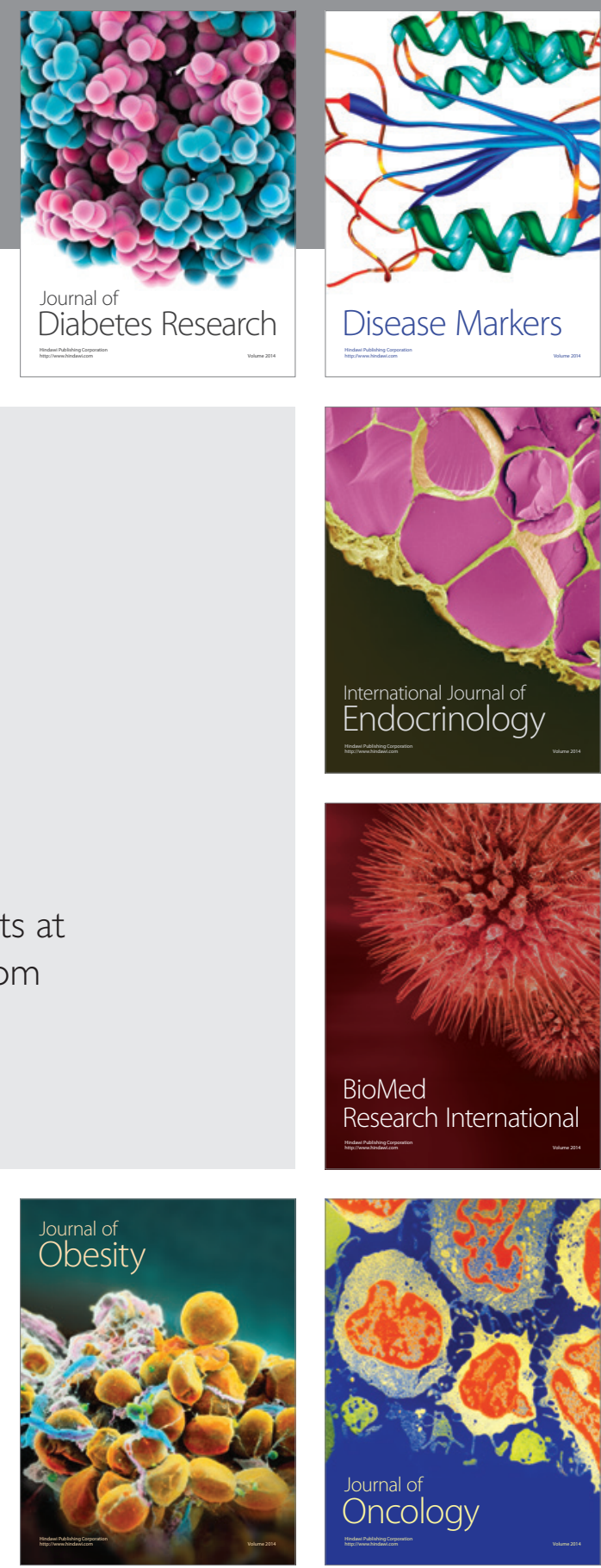

Disease Markers
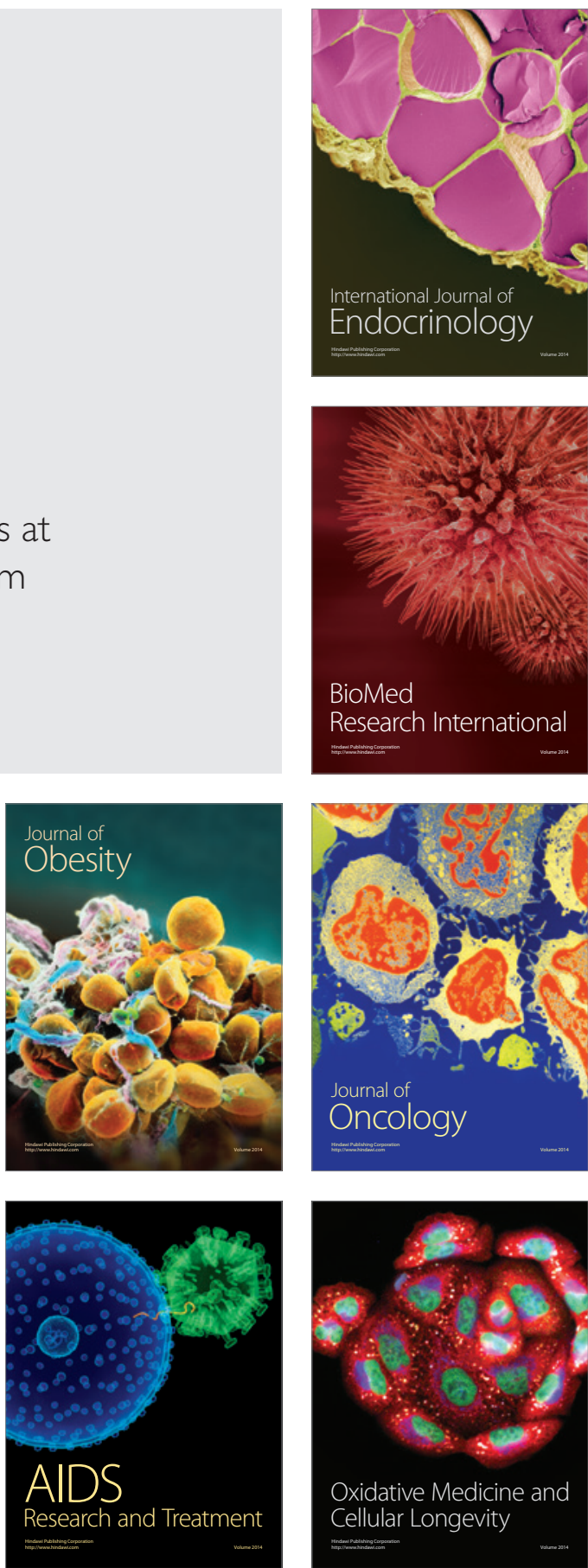